\title{
Self-regulation of consumer decision making and behavior: The role of implementation intentions
}

\author{
Peter M. Gollwitzer ${ }^{\mathrm{a}, \mathrm{b}, *}$, Paschal Sheeran ${ }^{\mathrm{c}}$ \\ a New York University, New York, New York, USA \\ ${ }^{b}$ Universität Konstanz, Konstanz, Germany \\ ${ }^{c}$ University of Sheffield, Sheffield, UK
}

\begin{abstract}
People may use the self-regulatory strategy of forming implementation intentions (i.e., if-then plans) to make better consumer decisions and facilitate the translation of those decisions into action. First, research on the mechanisms and effects of implementation intentions is reviewed. Second, we discuss how implementation intentions can be used to improve consumer decision making by promoting attention control and information elaboration, and overcoming disruptive influences. Third, we consider the various problems that militate against the enactment of one's decisions, and evidence is presented to show that implementation intentions are still effective even when goal attainment does not seem to be amenable to self-regulation. Finally, potential moderators of implementation intention effects are discussed.
\end{abstract}

Research on consumer decision making and behavior focuses on what determines a person's decisions and whether such decisions are translated into action. Accumulated evidence suggests that consumers' decisions are strongly affected by the information presented and how willing and able perceivers are to process that information. For instance, it matters whether information about a given product uses images or words, general versus detailed statements, or emotional versus factual content (e.g., Kramer \& Yoon, 2007; Wyer, Hung, Jiang, 2008; Yoon, Cole, \& Lee, 2007). Whether one or the other type of information has greater impact on people's decisions is influenced by features of the recipients such as their cognitive capacity, motivation, mood, age, inter alia. The enactment of consumer decisions, on the other hand, has been found to depend on features of the situational context in which action is initiated (e.g., the presence of barriers, distractions, bad habits, and social support), the strength of the person's commitment to purchasing the item (e.g., persistence in obtaining the product), and available resources (e.g., credit rating or negotiation skills).

\footnotetext{
* Corresponding author. Psychology Department, New York University, 6 Washington Place, 7th Floor, New York, NY 10003, USA.

E-mail address: peter.gollwitzer@nyu.edu (P.M. Gollwitzer)
}

This paper proposes that people can control the influence of such determinants on consumer decision making and decision realization by adopting a self-regulatory strategy called implementation intentions (i.e., if-then plans). Using this strategy, people plan out in advance exactly how they will respond in situ. In the case of decision making, such plans may pertain to how deeply presented information is processed (e.g., in a systematic rather than a heuristic fashion) or how much weight should be attached to different types of information (e.g., affective versus cognitive). In the case of decision realization, such plans may specify how to get started with enacting the consumer decision (e.g., planning the time and place of purchase) or how to shield decision enactment from disruptive influences (e.g., dealing with a domineering salesperson). In other words, we will suggest that if-then plans that specify do's and don'ts of effective decision making and decision implementation can facilitate good consumer decisions and behavioral enactment. By using if-then plans in this way, people can avoid being passive victims of internal shortcomings or external obstacles to effective decision making and decision enactment. Rather, by anticipating these shortcomings and obstacles, and planning out in advance how to overcome them, consumers can take an active role in both phases of the decision process. 
What are implementation intentions and how do they work?

\section{Nature and effects of implementation intentions}

Implementation intentions are if-then plans formed for the purpose of meeting one's goals (Gollwitzer, 1993, 1999; Gollwitzer \& Sheeran, 2006). To form an implementation intention, one needs to identify a future goal-relevant situational cue (e.g., a good opportunity to act or an obstacle to goal pursuit) and a related goal-directed response to that cue (e.g., how to respond to the opportunity or how to overcome the obstacle). Whereas goal intentions merely specify desired end states ("I want to achieve goal X!"), implementation intentions have the format "If situation $\mathrm{Y}$ arises, then I will initiate behavior Z!" The if-component of the plan specifies when and where one will pursue a goal, whereas the then-component of the plan specifies how this will be done. Implementation intentions thus delegate control over the initiation of the intended goal-directed behavior to a specified opportunity by creating a strong link between a situational cue and a goaldirected response. For example, a person who has the goal to save for retirement can form the implementation intention "If it is the end of the month and some money is left in my checking account, then I'll move it to the savings account!"

Implementation intentions have been found to help people close the gap between setting goals and actually realizing these goals. For instance, epilepsy patients who formed the plan "If it is (self-chosen time) and I am at__ (self-chosen location) and I do ___ (self-chosen activity), then I will take my pill dose of the day!" were much more likely to take their medication on time than were control participants who had equivalent strong goal intentions to take their medication. An objective measure of drug adherence over 1 month indicated that whereas only $55 \%$ of the control participants took their medication on schedule, $79 \%$ of implementation intention participants did so (Brown, Sheeran, \& Reuber, in press). Evidence that forming if-then plans enhances rates of goal attainment and behavioral performance has now been obtained in several studies. A recent meta-analysis involving over 8000 participants in 94 independent studies revealed a medium-tolarge effect size $(d=.65$; Cohen, 1992) of implementation intentions on goal achievement in a variety of domains (e.g., interpersonal, environmental, and health) on top of the effects of mere goal intentions (Gollwitzer \& Sheeran, 2006). The size of the implementation intention effect is noteworthy, given that goal intentions by themselves already have a facilitating effect on behavior enactment (Webb \& Sheeran, 2006).

People benefit from forming implementation intentions when they are confronted with crucial problems of goal implementation: failing to get started, getting derailed, overextending oneself, and failing to call a halt to fruitless goal striving. Numerous studies suggest that problems of getting started on one's goals can be solved effectively by forming implementation intentions, as they help to initiate goal-directed action even at inconvenient times (e.g., during holidays; Gollwitzer \& Brandstätter, 1997; Study 2), when there is an initial reluctance to get started (e.g., to eat a low-fat diet, Armitage, 2004), and when it is easy to forget to act (e.g., regular intake of vitamin pills; Sheeran \& Orbell, 1999). But many goals cannot be accomplished by simple discrete one-shot actions but require that people keep striving for the goal over an extended period of time. Such staying on track may become very difficult when certain external stimuli (e.g., temptations or distractions) or internal stimuli (e.g., being anxious, tired, or overburdened) interfere with and potentially derail ongoing goal pursuit. Implementation intentions of different formats have been found to effectively shield ongoing goal striving from such interference. For instance, implementation intentions can be geared at shielding goal striving from unwanted influences by specifying a simple ignore-response (e.g., Achtziger, Gollwitzer, \& Sheeran, 2008; Study 1) or more elaborate coping responses (e.g., substitution or re-engagement; Achtziger et al., 2008; Study 2). An alternative way of using implementation intentions to protect ongoing goal striving from derailment from inner or outer distractive stimuli is to form implementation intentions geared toward stabilizing the ongoing goal striving; that is, the precise manner in which the focal goal is to be pursued is spelled out in advance via if-then plans (Bayer, Gollwitzer, \& Achtziger, 2009). The self-regulatory problem of overcoming self-defensiveness when having to call a halt to a futile goal striving (e.g., disengaging from a means that turns out to be faulty, even though the means was chosen mindfully; Bobocel \& Meyer, 1994) has also been found to benefit from forming implementation intentions (Henderson, Gollwitzer, \& Oettingen, 2007). And finally, self-regulatory resources (Muraven \& Baumeister, 2000) are found to stay preserved when goal striving is regulated by implementation intentions, and thus for individuals using implementation intentions, not overextending oneself becomes easier (Webb \& Sheeran, 2003; Martijn, Alberts, Sheeran, Peters, Mikolajczak, \& de Vries, 2008).

\section{Mechanisms of implementation intention effects}

Research on the underlying mechanisms of implementation intention effects has discovered that implementation intentions facilitate goal attainment on the basis of psychological processes that relate to the anticipated situation (specified in the if-part of the plan), the intended behavior (specified in the then-part of the plan), and the mental link forged between the ifpart and the then-part of the plan. Because forming an implementation intention implies the selection of a critical future situation, the mental representation of this situation becomes highly activated and hence more accessible (Gollwitzer, 1999). This heightened accessibility of the if-part of the plan has been observed in several studies (e.g., Aarts, Dijksterhuis, \& Midden, 1999; Parks-Stamm, Gollwitzer, \& Oettingen, 2007; Webb \& Sheeran, 2007, 2008). The heightened activation of the critical situation helps people to easily detect their moment for acting (e.g., Webb \& Sheeran, 2004; Wieber \& Sassenberg, 2006) even when attention is otherwise absorbed (Achtziger, Bayer, \& Gollwitzer, 2009). Recent studies indicate that the strong associations forged by implementation intentions between the specified opportunity 
and the specified response (Webb \& Sheeran, 2007, 2008) are quite stable over time (Papies, Aarts, \& de Vries, in press). Findings also showed that subliminal presentation of the specified critical situational cues (if-component) primed mental representations of the specified response (the plan's thencomponent). Moreover, mediation analyses revealed that cue accessibility and the strength of the cue-response link together explained the impact of implementation intention formation on goal attainment (Webb \& Sheeran, 2007, 2008).

The upshot of these strong links is that, once the critical cue is encountered, the initiation of the goal-directed response specified in then-component of the implementation intention exhibits features of automaticity including immediacy, efficiency, and redundancy of conscious intent. When people have formed an implementation intention, they can act in situ without having to deliberate on when and how they should act. Evidence that if-then planners act quickly (Gollwitzer \& Brandstätter, 1997, Experiment 3), deal effectively with cognitive demands (i.e., speed-up effects are still evidence under high cognitive load; Brandstätter, Lengfelder, \& Gollwitzer, 2001; Lengfelder \& Gollwitzer, 2001), and do not need to consciously intend to act in the critical moment is consistent with this idea (i.e., implementation intention effects are observed even when the critical cue is presented subliminally; Bayer, Achtziger, Gollwitzer, \& Moskowitz, 2009; or when the respective goal is activated outside of awareness; Sheeran, Webb, \& Gollwitzer, 2005; Study 2). These component processes of implementation intentions (enhanced cue accessibility, strong cue-response links, and automation of responding) mean that if-then planning enables people to see and seize good opportunities to move towards their goals. Fashioning an if-then plan thus strategically automates goal striving; people intentionally make if-then plans that delegate control of goal-directed behavior to pre-selected situational cues with the explicit purpose of reaching their goals.

This delegation hypothesis has recently been supported by studies that collected brain data (EEG, fMRI). Schweiger Gallo, Keil, McCulloch, Rockstroh, and Gollwitzer (2009; Study 3) used dense-array electroencephalography. Behavioral data indicated that implementation intentions that specified an ignore-response in the then-component helped control fear in response to pictures of spiders among participants with spider phobia; importantly, the obtained electrocortical correlates revealed that those participants who bolstered their goal intention to stay calm with an ignore-implementation intention showed significantly reduced early activity in the visual cortex in response to spider pictures, as reflected in a smaller P1 (assessed at $120 \mathrm{~ms}$ after a spider picture was presented). This suggests that implementation intentions indeed lead to strategic automation of the specified goal-directed response (in the present case an ignore-response) when the critical cue (in the present case a spider picture) is encountered, as conscious effortful action initiation is known to take longer than $120 \mathrm{~ms}$ (i.e., at least $300 \mathrm{~ms}$; see Bargh \& Chartrand, 2000).

Moreover, further support for the delegation hypothesis was obtained by Gilbert, Gollwitzer, Cohen, Oettingen, and Burgess (2009). In an fMRI study that involved a prospective memory task, they observed that acting on the basis of mere goal intentions was associated with brain activity in the lateral rostral prefrontal cortex, whereas acting on the basis of implementation intentions was associated with brain activity in the medial rostral prefrontal cortex. Brain activity in the latter area is known to be associated with bottom-up (stimulus) control of action, whereas brain activity in the former area is known to be related to top-down (goal) control of action.

Finally, the delegation hypothesis concerning the operation of implementation intentions has also been supported by studies using critical samples, that is, individuals with poor selfregulatory abilities such as people with schizophrenia, people with substance abuse disorders, and children with ADHD (Brandstätter et al., 2001, Studies 1 \& 2; Gawrilow \& Gollwitzer, 2008; Paul et al., 2007). For instance, Brandstätter et al. (2001) asked hospitalized opiate addicts under withdrawal to write a short CV before the end of the day; half of the participants formed relevant implementation intentions (they specified when and where they would start to write what), and the other half (control group) formed irrelevant implementation intentions (when and where they would eat what for lunch). Eighty percent of the relevant implementation intention participants had written a short $\mathrm{CV}$ at the end of the day, whereas none of the participants with the irrelevant implementation intention succeeded in doing so.

\section{Summary}

Implementation intentions help people to cope more effectively with the major problems of goal striving: getting started, staying on track, calling a halt, and not overextending oneself. In a conscious act of will ("If situation $\mathrm{x}$ arises, then I will show behavior $y$ !"), people link an anticipated critical internal or external cue to a goal-directed response. The latter then becomes automatically triggered in the presence of the critical cue. Thus implementation intentions can be used to facilitate the attainment of all kinds of difficult goals, and for people who are known to have difficulties with action control.

One may be tempted to argue that behavior change by planning has been studied extensively in the context of cognitive behavior therapy for quite some time-so why not capitalize on these insights? A closer look at the cognitivebehavioral approach to behavior modification reveals, however, that it focuses on readying people for change (e.g., Beck, 1995; Miltenberger, Fuqua, \& Woods, 1998; Prochaska, DiClimente, $\&$ Norcross, 1992). People are asked to monitor the occurrence (critical situations, frequency) and positive/negative consequences of an unwanted behavior and reflect on what kind of wanted behaviors could potentially replace it. The potential replacement behaviors are then scrutinized in terms of their feasibility and desirability (positive/negative consequences), and first attempts to implement them are monitored carefully and rewarded to improve performance (e.g., Baker \& Kirschenbaum, 1998). From the perspective of research on implementation intentions, all of this is geared towards motivating people to set themselves the goal of replacing an unwanted dysfunctional behavior with a wanted functional 
behavior. Not surprisingly then it is the person's beliefs (feasibility, desirability) that are targeted, whereby irrational beliefs are replaced by more rational ones (Beck, 1995).

Implementation intention research on the other hand is geared towards understanding how people can improve their striving for goals they have already set for themselves. It is no longer the setting of goals that is at issue, but rather their effective implementation. As a consequence, changing people's beliefs about the feasibility and desirability of the set goal becomes secondary; the focus is now on how people can effectively deal with the typical problems of goal striving so that the rate of goal attainment increases. It is suggested that people employ the self-regulation tool of forming if (critical situation)then (goal-directed response) links, making goal striving directly controlled by the presence of critical cues.

\section{How can implementation intentions be used to enhance consumer decision making?}

When people make consumer decisions, it is in their hands how they deal with incoming information propagating particular products. For instance, messages may contain strong versus weak arguments, delivered by sources that differ in likeability and credibility (e.g., Chaiken, 1979; Cooper \& Neuhaus, 2000; Petty, Caccioppo, \& Goldman, 1981). Accordingly, implementation intentions can guide a person's attention to those features of a persuasive message that facilitate good decisions (e.g., strong over weak arguments or credible over likeable sources). Moreover, people can process the incoming information in a deep or shallow manner thus taking a systematic or central route versus a heuristic or peripheral route (e.g., Chen \& Chaiken, 1999; Petty \& Wegener, 1999). Here, implementation intentions can be used to favor taking one route over the other (e.g., elaborating good arguments and ignoring peripheral cues). People's attitudes can be changed not only by persuasive communications but also by inducing experience with the consumer product. In this instance, implementation intentions can be used to promote engagement in behaviors that provide such valuable experience (i.e., persuasion by our own actions; e.g., Higgins \& Rholes, 1979; Janis, 1968). Finally, even if people are ready to attend to the important aspects of incoming information and willing to process this information deeply, there may be a variety of unwanted influences that can militate against optimal attention to, and elaboration of, the message. Important among these factors are mood, ego-depletion, implicit stereotypes and attitudes, cravings, and emotional reactivity. In this case, implementation intentions would need to be geared either at suppressing these influences or at controlling attention and elaborative responses so that they are no longer vulnerable to such influences (Gollwitzer, Bayer, \& McCulloch, 2005; Gollwitzer \& Sheeran, 2006).

Although implementation intention research has not so far been specifically targeted at studying these issues in the domain of consumer decision making, several studies have addressed attention control, information elaboration, controlling unwanted influences, and gaining direct experience, by the use of if-then plans.

\section{Attention control}

Recent studies have examined whether implementation intention formation can be used to control attention responses among socially anxious people (Webb, Onanaiye, Sheeran, Reidy, \& Lavda, in press). Such individuals are known to attend automatically to threatening information (e.g., words such as 'blush' or 'evaluate'; e.g., Musa, Lepine, Clark, Mansell, \& Ehlers, 2003), and thus fail to attend to task-relevant information when threatening information is interspersed. Webb et al. (in press; Study 1) used a visual dot probe task to measure attention. In this task, two words are presented simultaneously on a computer screen and one is replaced either by the letter E or the letter F. Some words represent social threat (e.g., stupid or pathetic) whereas others are neutral words matched for length and frequency. Participants' task is to indicate which letter was presented. A measure of attentional bias is derived by comparing reaction times to probes ( $\mathrm{E}$ or $\mathrm{F}$ ) that replaced social threat versus neutral words, based on the rationale that detection latencies are shorter in the attended area (Navon \& Margalit, 1983).

Findings showed that socially anxious participants who formed an if-then plan to pay attention to neutral information ("If I see a neutral word, then I will focus all of my attention on it!") no longer exhibited the characteristic attentional bias to threatening information. In fact, their attention to neutral information was equivalent to that of a non-socially anxious control group. A second study confirmed that participants who formed goal intentions to attend to neutral words exhibited less successful attention control than did implementation intention participants who received identical instructions that were framed in the format of an if-then plan (i.e., if-then plan effects were not due to greater information about how to undertake the task). Finally, because there is some doubt about whether performance on the visual dot probe task reflects increased orientation towards threat or an inability to disengage from threatening information, a third study used a paradigm that unambiguously measured attention disengagement (Fox, Russo, Bowles, \& Dutton, 2001). Again, findings showed that participants who formed implementation intentions exhibited greater attention control in terms of withdrawing attention compared to participants who formed mere goal intentions.

Other studies have shown that forming implementation intentions can prevent alluring stimuli from taking attention away from an ongoing task that demands much concentration. Participants had to solve taxing arithmetic problems while being repeatedly exposed to attractive, award-winning commercials. Gollwitzer and Schaal (1998) tested the efficacy of two types of implementation intentions in promoting task performance. In the goal intention condition, participants only formed the intention to not let themselves get distracted. The two implementation intention conditions furnished this goal intention with if-then plans that specified how they would respond when a distraction was experienced. The first implementation intention group planned to work harder in the presence of distractions ("As soon as I see moving pictures or hear sounds, then I will increase my efforts on the arithmetic tasks!"; task- 
facilitating plan) whereas the second implementation intention group planned to simply ignore the distractions ("As soon as I see moving pictures or hear sounds, then I will ignore them!"; temptation-inhibiting plan). Findings showed that both types of implementation intentions engendered better task performance compared to the goal intention condition. Interestingly, the temptation-inhibiting plan promoted performance even more than task-facilitating implementation intentions, a finding that is in line with earlier work by Mischel and Patterson (1978). A further test of the power of specifying an ignore-response in the then-part of an implementation intention was conducted by Palayiwa, Sheeran, and Thompson (in press): Forming implementation intentions to ignore stigmatizing comments about personal appearance meant that participants performed just as well on a standard measure of attention ( $d 2$, Brickenkamp \& Zillner, 1998) as did control participants who did not have to listen to stigmatizing material while performing the attention task; mere goal intentions to ignore the stigmatizing comments turned out to be ineffective.

\section{Information elaboration}

Even if the information on a consumer product is attended to, a good decision may still not be possible because the person fails to elaborate on the information presented (i.e., does not carefully consider the implications of the message). Such deep processing should also benefit from implementation intentions when the then-component of the plan specifies a response that facilitates elaboration. Two lines of research speak to this possibility.

Wieber, Odenthal, and Gollwitzer (in press) analyzed whether implementation intentions can be used to enhance elaborated processing of available information in the context of taking an intelligence test. Participants worked on difficult Advanced Progressive Matrices (APM, Set II; Raven, 1976); matrices were selected following the criterion that they were vulnerable to oversight (i.e., picking the first answer that comes to mind) and thus should benefit from a double-checking strategy (i.e., more elaborated processing). All participants formed the goal intention "I want to solve as many items as possible!" In addition, half of the participants were asked to include a double-checking strategy in an implementation intention "And if I have found an initial solution, then I will double check it!" Findings showed that this implementation intention to double check an initial solution paid off. Implementation intention participants out-performed mere goal intention participants. Mediation analyses revealed that the performance advantage of implementation intentions was entirely mediated by taking more time before indicating one's answer. Thus it appears that implementation intentions can be used to specify strategies that allow for more elaborate processing of available information, and that this elaborated processing in turn affects the quality of the decisions made.

Henderson, Gollwitzer, and Oettingen (2007) analyzed whether people can use implementation intentions to arrive at disengagement decisions that respect complex performance feedback. Participants chose one of various possible test-taking strategies to perform well on a general knowledge test. Next, participants justified why they chose their particular strategy; this procedure has been shown to reliably produce escalation of commitment effects (i.e., failure to disengage form a failing course of action; Bobocel \& Meyer, 1994). There were two control conditions: no-instruction control participants started the test with no additional instructions. Goal intention control participants were asked to form the goal intention to always use the best strategy during the test. There were also two implementation intention conditions: an action implementation intention ("And if I receive disappointing feedback, then I'll switch my strategy!") and a reflection implementation intention ("And if I receive disappointing feedback, then I'll think about how things have been going with my strategy!"). After initial success feedback participants received failure feedback regarding their performance on the test, and were then asked whether they wanted to switch to a different strategy. Two failure feedback conditions were established: Failure feedback either got worse and worse over time or it got worse and then better.

Findings showed that the action implementation intention fostered high rates of disengagement regardless of whether feedback indicated that performance would ultimately get worse or better. In contrast, the reflection implementation intention promoted sensitivity to the direction of failure feedback; a reflection implementation intention facilitated disengagement when the outlook was poor but maintained engagement when the outlook was good. Finally, control and mere goal intention participants were unable to make use of the failure feedback; they were unable to disengage (i.e., showed the classic escalation of commitment effect). This pattern of findings suggests that implementation intentions can be used to elaborate on the information presented, so that participants can understand and use complex feedback to make high quality behavioral decisions. A follow-up study (Henderson et al., 2007; Study 2) showed that this elaboration by implementation intentions even holds when time pressure is put on participants' decision making.

\section{Overcoming unwanted influences on the decision making process}

A variety of factors can undermine the quality of decision making by affecting the depth of information processing and the weight that is attached to different kinds of information in arriving at a decision (e.g., down-regulating the impact of affective appeals). Important among these factors are internal states such as mood and ego-depletion, and spontaneous cognitive and affective responses to critical cues (e.g., implicit stereotypes and attitudes, cravings, and emotional reactivity).

\section{Mood}

Positive mood is known to promote heuristic information processing (Bless, 2001; Bless \& Fiedler, 1995). For example, people are more likely to use stereotypes in judging others when they are in a good mood compared to a neutral mood. Bayer, Gollwitzer, \& Achtziger, (2009; Study 1) tested whether implementation intentions can be used to undermine the characteristic impact of positive mood on stereotyping and 
instead promote analytic processing. Participants were put in a positive or neutral mood by watching a humorous movie or a documentary film, and then viewed illustrations of women performing one of two actions: One woman was sitting in front of a mirror, and the other was shouting at a child attempting to walk a tightrope. Both scenarios were accompanied by four descriptions of the event, and participants had to choose the one they thought matched best. These descriptions varied in terms of their stereotypicality versus focus on detail (e.g., "this woman is vain" versus "this woman combs her hair," and "this woman is caring" versus "this woman hollers at a child"; Semin \& Fiedler, 1991). When participants' chosen descriptions were analyzed, findings showed that positive mood indeed facilitated stereotypical descriptions. However, forming implementation intentions geared at evaluating women in a non-stereotypical manner ("If I start to evaluate a depicted character, then I will ignore the character's gender!") completely eliminated this mood effect. Importantly, mere goal intentions to form non-stereotypical impressions did not suffice to overcome the impact of positive mood.

Evidence that implementation intentions can also overcome the negative impact of the arousal component of mood on decision making comes from a study by Webb, Sheeran, Totterdell, Mansell, and Baker (2009; Study 2). High versus low arousal was induced by having participants listen to a lively versus soothing piece of music for $5 \mathrm{~min}$. Next, participants undertook a computerized decision making task. Participants were given 100 points and made bets in order to win further points. Performing well on the task requires that participants wait for extensive feedback before placing bets, and bet more of their points when feedback indicates that there is a higher probability of winning (Rogers et al., 1999). Findings showed that arousal had an important impact on the number of points won: More aroused participants performed worse compared to less aroused participants. However, when participants formed implementation intentions aimed at promoting deeper processing of the presented feedback ("If I am asked to make a bet, then I pay close attention to the odds of winning!"), the impact of arousal on decisions was abolished. In sum, implementation intentions can be used to ensure that information processing remains detailed and analytic even when mood favors heuristic processing, and that decisions are not unduly swayed by the experience of arousal.

\section{Ego-depletion}

Recent research on ego-depletion (i.e., reduced capacity for subsequent self-control following an initial exertion of selfcontrol) shows that engaging in decision making can cause egodepletion, and that being ego-depleted may hinder good-quality decision making (Vohs et al., 2008). However, implementation intention research has found that both the emergence of egodepletion can be avoided by forming implementation intentions and the negative impact of being ego-depleted on performance can be overcome (Bayer, Gollwitzer, \& Achtziger, 2009; Study 2; Webb \& Sheeran, 2003). With respect to the emergence of ego-depletion, Webb and Sheeran (2003; Study 1) asked participants either to form mere goal intentions ("Name the color in which the word is written!") or additional implementation intentions ("As soon as I see a word, I will ignore its meaning!") and then perform a classic Stroop task. Subsequently, all participants undertook an unsolvable puzzles task, and their persistence was measured. Findings indicated that participants who formed implementation intentions persisted for a longer time compared to goal intention participants. Study 2 examined whether implementation intentions could offset the consequences of ego-depletion. Participants were ego-depleted by standing on their weaker leg and counting back from 1000 in sevens, or stood normally and counted to 1000 in fives (control condition). Next, all participants undertook the Stroop task used in Study 1 under goal intention or implementation intention conditions. Manipulation checks indicated that the egodepletion manipulation was successful. Nonetheless, implementation intention participants showed improved performance compared to goal intention participants; in fact, they performed at the level exhibited by non-depleted controls. These findings suggest that people can use implementation intentions to protect themselves from ego-depletion effects associated with decision making. This pertains to both the emergence of ego-depletion caused by making difficult decisions and to the consequences of ego-depletion for making good decisions.

\section{Implicit stereotypes and implicit attitudes}

Effective consumer decision making may be undermined by the direct activation of stereotypes and attitudes. That is, overlearned associations between group membership and particular traits and preferences (e.g., between older age and preference for less complex products) could exert an unintended, automatic impact on decisions (e.g., a salesperson immediately recommends a less complex electronic device to an elderly consumer). Is it possible for people to ensure that implicit stereotypes and attitudes no longer exert such negative impacts by using implementation intentions? Studies have tested two routes by which such control can be achieved.

First, Gollwitzer and Schaal (1998; see also Stewart \& Payne, 2008) investigated whether forming if-then plans could prevent activation of implicit stereotypes. Participants took the role of a personnel manager in a simulated hiring session and were assigned the goal to judge women applicants in a fair and non-stereotypical manner. The pool of applicants included two men and two women (called Ina and Bea). In the implementation intention condition, participants were asked to tell themselves "And whenever I see Ina, I will ignore her gender!" Participants expected to meet the applicants but prior to this supposed meeting, participants were asked to complete a computerized task. The computer task was a primed Stroop task wherein the target words (gender-stereotypical and genderneutral attributes) were presented in four different colors that participants had to name as quickly as possible. The target words were presented less than $300 \mathrm{~ms}$ after the onset of the prime words (i.e., INA, BEA, and a control prime of the letter string $\mathrm{CCC}$ ) thus precluding effortful control.

Results showed that with goal intention participants, the primes INA and BEA significantly reduced the latency of color naming responses to gender-stereotypical words, indicating that 
INA and BEA implicitly activated gender stereotypes despite participants having been assigned the goal to be fair. Implementation intention participants, on the other hand, only showed such reduction in response latencies when BEA was used as the prime. When INA (the target person specified in the implementation intention) was the prime, participants were successful in suppressing automatic stereotype activation.

The second route by which implementation intentions could control implicit stereotypes and attitudes is by preventing their expression. This route was tested by Webb, Sheeran, and Pepper (2009; see also Mendoza, Gollwitzer, \& Amodio, 2009). A first experiment examined associations between Muslim (vs. Scottish) names and terrorism (vs. peace) words using the Go/ No-Go Association Test (GNAT; Nosek \& Banaji, 2001). Control participants completed the task under standard instructions; as expected, these participants showed a much stronger association between Muslim names and terrorism words (e.g., bomb or attack) than between Muslim names and peace words (e.g., friendship or love). However, participants who formed implementation intentions to control their expression of Muslim-peace associations on the GNAT ("If Muslim names and peace are at the top of the screen, then I respond especially fast to Muslim words and peace words!") no longer exhibited this difference. In fact, Muslim-peace associations were just as strong as Scottish-peace associations when participants had formed implementation intentions.

Subsequent experiments used the implicit association task (IAT; Greenwald, McGhee, \& Schwartz, 1998) to measure the expression of participants' implicit attitudes. Experiment 2 examined associations between gender and science versus liberal arts disciplines (e.g., chemistry versus philosophy) under four conditions. Control participants received standard IAT instructions only. Goal intention participants were also told: "Most people associate females with liberal arts and males with science subjects. Your goal in the following experiment is NOT to stereotype women." Implementation intention participants received the standard and goal intention instructions, and also either formed an if-then plan on how to undertake the IAT task ("If female and science are paired at the top of the screen, then I will respond especially fast to both science and female words!"; task-facilitating plan) or formed an if-then plan to strengthen the counter-stereotypical association ("If I see a female word, then I will think science and if I see a science word, then I will think female!"; counter-stereotypical plan). Findings showed that control participants exhibited the characteristic strong association between women and liberal arts and men and science. Merely forming the goal intention not to stereotype was ineffective in preventing manifestation of this association, as control participants and goal intention participants showed equivalent IAT scores. Participants who formed implementation intentions, on the other hand, showed significantly less stereotypical IAT scores compared to the other two groups. Apparently, forming if-then plans of both types meant that participants could self-regulate the expression of their implicit associations, even though it is supposed to be very difficult to prevent such expression on tasks such as the GNAT and IAT. In sum, forming relevant implementation intentions should effectively emancipate consumer decisions from implicit stereotype and attitude effects by suppressing the implicit activation, or offsetting the negative effects, of these mental representations.

\section{Cravings}

The intrusion theory of desire (EITD; Kavanagh et al., 2005) proposes that the intrusive effects of cravings result from the fact that a strong affective reaction is experienced with respect to a given target (e.g., drugs and food) that provokes the experience of deprivation. As a result the craving-related thoughts will become intensified which in turn triggers attempts to down-regulate them in an effortful way. Ironically, this makes it more likely that additional internal/external cues are accessed and further intrusive thoughts are generated. The processing priority that is accorded to elaborating thoughts about the target explains why decisions geared at making progress towards superordinate goals (e.g., the dieting goal) are often undermined during craving episodes.

Can the elaboration of desire-relevant thoughts be prevented using implementation intentions? Achtziger, Gollwitzer, and Sheeran (2008; Study 1) tested this idea. First, all participants indicated the strength of their goal intention to reduce consumption of high fat snack foods. Then half of the participants were asked to form an implementation intention to ignore thoughts about that foodstuff (i.e., not elaborate them): "Please tell yourself: And if I think about a high fat snack food, then I will ignore that thought!" It was found that participants who had formed the if-then plan to ignore food-cravings showed a greater reduction in snack food consumption compared to control participants who did not form such an ifthen plan. Moreover, this implementation intention effect was more pronounced, the stronger was participants' goal intention to reduce snack food consumption. This finding suggests that people can use implementation intentions to effectively suppress craving thoughts when they deliberate on decisions pertaining to products that elicit urges to consume them.

\section{Emotional reactivity}

Consumer products often elicit spontaneous emotions (e.g., disgust) that make an analytical elaboration of the available information on these products difficult. Could implementation intentions help to keep a "cool" mind (Metcalfe \& Mischel, 1999) that allows for a distanced analysis of this information, or is a "hot" immersed analysis inevitable when powerful emotioneliciting cues are encountered? In a recent study by Schweiger Gallo et al. (2009), participants were told that they would be requested to view a number of slides and rate their emotional responses to each of these slides; participants were first exposed to four example slides (one of them presented an awful-looking bloody face), and then were asked if they wanted to participate. Next, participants were told that they would be asked to estimate their arousal after the presentation of each picture using the arousal Manikins of the SAM-scales that varied from excited (left side) to relaxed (right side). Different instructions were then given to participants in the goal intention and implementation intention conditions; control participants received no further 
instructions. Participants in the goal intention condition were asked to form the goal intention "I will not get disgusted!" Implementation intention participants were first asked to form this goal intention and then add the following if-then plan: "And if I see blood, then I will stay calm and relaxed!" Altogether, participants had to view 45 pictures in a fixed randomized order (15 of the pictures showed disgusting material such as bloody scenes of burn victims and mutilations, 15 presented pleasant material such as happy infants and appetizing food, and 15 showed neutral material such as household objects).

Findings showed that disgust can be controlled effectively by forming implementation intentions that support a respective goal intention. Specifically, when a goal intention ("I will not get disgusted!") was furnished with an implementation intention ("And if I see blood, then I will remain calm and relaxed!") arousal ratings of disgusting pictures were reduced compared to forming only a goal intention or no goal intention at all (control condition). The goal intention did not achieve the desired reduction of arousal; arousal in the control condition and the goal intention condition were high and close to identical.

Interestingly, the achieved down-regulation of arousal by implementation intentions with respect to disgusting pictures did not involve any costs in terms of experiencing excitement with respect to pleasant pictures. Pleasant pictures led to the same arousal levels as observed in the goal intention and control conditions. Also, the arousal level reported for neutral pictures stayed unaffected. It is also important to note that implementation intentions managed to reduce the arousal induced by disgust pictures to a level that was close to that observed for pleasant pictures. In other words, down-regulation of disgust via implementation intentions is not only very effective (as compared to control and goal intention individuals); it also does not spill over so that one can no longer get excited about pleasant stimuli (i.e., implementation intention effects are specific in the sense of only applying to the stimuli spelled out in the if-part of the plan).

Further evidence that implementation intentions enable people to gain control over even strong emotions comes from research concerning the impact of feelings of shame and embarrassment on attendance for mental health appointments. Sheeran, Aubrey, and Kellett (2007) surveyed individuals who were waiting for a psychotherapy appointment regarding their beliefs about the affective costs and perceived benefits of attending for psychotherapy. One-half of the sample formed implementation intentions geared at ensuring that participants would not use negative feelings about attendance as information in guiding their decision to keep their appointment ("As soon as I feel concerned about attending my appointment, I will ignore that feeling and tell myself this is perfectly understandable!"). Findings showed that participants who formed implementation intentions were more likely to attend their appointment than were controls ( $75 \%$ versus $63 \%$ ). Regression analyses indicated that anticipated feelings of shame and embarrassment were a powerful predictor of attendance among the control group. However, when participants believed that attendance would be beneficial and had formed respective implementation intentions, then such affective costs of attendance no longer predicted attendance. Implementation intentions apparently abolished the impact of these powerful negative feelings on participants' attendance behavior.

\section{Gaining direct experience}

Evidence indicates that direct experience produces attitudes that are both favorable and strong (i.e., stable and highly predictive of behavior; see Fazio \& Zanna, 1981). A recent experiment by Kardes, Cronley, and Posavac (2005) examined whether implementation intentions could be used to increase consumers' direct experience with a new product, and thereby increase liking for the product and promote stronger purchase intentions. During an initial session, participants all received a demonstration of a new household cleaning product and an explanation of the product's benefits, before being assigned to implementation intention versus control conditions. Implementation intention participants received a calendar wherein they specified exactly when, where, and for what purposes they would use the product. Control participants indicated whether or not they would try the product. At the end of the session, all participants received a free sample of the new product to try at home.

Two weeks later, participants received a questionnaire by mail and reported how much they had used the product since the first session, and their current attitudes and intentions regarding the product. Findings indicated that, compared to controls, implementation intention participants used the product twice as often and used more than three times the amount of the product. Consistent with the idea that direct experience promotes more favorable attitudes and intentions, participants who formed implementation intentions also showed greater liking for the product and reported that they were more likely to buy the product in the future. Kardes et al.'s (2005) study is an innovative deployment of implementation intentions as it appears to be the first study to use this self-regulation strategy to promote attitude and intention change.

\section{How can implementation intentions be used to facilitate consumer decision enactment?}

As pointed out above in the section on what implementation intentions are and how they work, implementation intentions can help people to get started with their goals, to shield goal striving from getting derailed, to disengage from chosen but futile means, and to preserve self-regulation resources. All of this should make it easier for people to enact their consumer decisions (e.g., saving for a house, shopping for organic food, and buying an environmentally-friendly car). Still, one wonders how action control by implementation intentions fares under conditions when action is primarily determined by factors that do not appear to be amenable to self-regulation. This question and a recent line of research have been stimulated by Aristotle's concept of akrasia (lack of will power), as any willful strategy of goal striving (such a if-then planning) has to prove itself under conditions where people commonly fail to demonstrate willpower. Such conditions are manifold and this research has 
focused on the following three: (a) situations in which a person's knowledge and skills constrain performance such as taking academic tests, (b) situations in which an opponent's behavior limits one's performance such as negotiation settings, and (c) situations in which the wanted behavior (e.g., no littering) runs into conflict with habits favoring an antagonistic response.

\section{Academic test performance}

Performance on academic tests (math tests, general intelligence tests) is by design determined primarily by a person's knowledge, analytic capability, and cognitive skills. To increase test scores by willpower, a person thus may want to focus on motivational issues such as staying concentrated on the various test items throughout the test or by reducing worry cognitions (e.g., Did I find the right answer on the last item?) and selfdoubts (e.g., Do I have the skills to find the right solution for the item at hand?). Bayer and Gollwitzer (2007; Study 1) asked female high school students to take a math test (composed by high school math teachers) under one of two different instructions. Half of the participants were asked to form the mere achievement goal intention: "I will correctly solve as many tasks as possible!" The other half of the participants had to furnish this goal intention with a self-efficacy-strengthening implementation intention "And if I start a new task, then I will tell myself: I can solve this task!" Participants in the implementation intention group showed better performance in the math test (in terms of number of tasks solved correctly) than participants in the mere goal intention condition, indicating that self-efficacy-strengthening implementation intentions facilitate successful goal striving in a challenging achievement situation.

Implementation intentions are usually constructed by specifying a situational cue in the if-part and linking it to goal-directed cognitive or behavioral responses in the then-part. In the present study, a critical situational cue (i.e., starting a new test item) in the if-part was linked to a motivational response (i.e., a self-efficacy-strengthening statement) in the then-part. Interestingly, this pre-programmed, inner self-motivating speech sufficed to produce better test performance. This suggests that implementation intentions can be used to ameliorate also motivational problems of goal implementation (such as self-doubts) and thus increase a person's willpower (i.e., the potential to exert self-control).

The present manipulation to increase willpower was particularly parsimonious, as we only had participants asked to form a plan in respect to when they will have to execute an inner self-efficacy-strengthening statement. Still, these findings leave open a pressing question: Does this inner speech need to take the format of an implementation intention? Maybe it suffices that participants simply form a goal intention geared towards holding up self-efficacy, such as "And I will tell myself: I can solve these problems!" To explore this possibility, a follow-up study was conducted that included this further control condition (i.e., a self-efficacy strengthening goal intention condition). Using the Raven Intelligence Test, Bayer and Gollwitzer (2007; Study 2) found that performance on the test improved only when participants were instructed to form self-efficacy strengthening implementation intentions; selfefficacy enhancing goal intentions did not work. This finding is important for several reasons. First, many of the field and laboratory studies investigating the benefits of implementation intentions (e.g., on health behaviors, job safety, and environment protection; see meta-analysis by Gollwitzer \& Sheeran, 2006) do not use an additional condition that spells out the thenpart of the implementation intention in terms of a goal intention (for an exception see Oettingen, Hönig, \& Gollwitzer, 2000). Therefore, in these studies the benefits of implementation intentions as compared to mere goal intentions could potentially be based on having access to additional information on how to act. With the present study, however, we can confidently rule out this alternative account as specifying the strategy of strengthening one's self-efficacy in terms of forming a goal intention did not lead to higher test scores. Only when this strategy was suggested to participants in the format of an if-then plan, positive effects on test performance emerged.

\section{Dealing with opponents}

Often our performances are constrained by others who are competing with us for positive outcomes. Typical examples are negotiations in which a common good has to be shared between two opposing parties. In such situations exerting willpower involves effectively protecting one's goal striving from unwanted influences generated by the competitive situation. Negotiations are cognitively very demanding tasks in which a large amount of information has to be processed on-line and the course of events is hard to predict as one is not performing a task alone but conjointly with an opponent. Thus, negotiations can be understood as the prototype of a complex situation in which striving for desired goals can easily become derailed. Therefore, analyzing whether the beneficial effects of implementation intentions found in previous research also hold true in negotiations is of great interest to assess whether needed willpower accrues from forming if-then planning (see also Martin, Sheeran, Slade, Wright, \& Dibble, in press).

In their negotiation research, Trötschel and Gollwitzer (2007) explored whether the self-regulation strategy of forming implementation intentions enables negotiators to find agreements even if they have to operate under the adverse conditions of a loss frame (i.e., participants see how many points they lose rather than win during each round and thus they are reluctant to make concessions; e.g., Bottom \& Studt, 1993; Olekalns, 1997). In one of their experiments, pairs of negotiators were assigned the role of representatives of two neighboring countries (i.e., the blue and the orange nations) and asked to negotiate the distribution of a disputed island (i.e., its regions, villages, and towns). One group of pairs of negotiators was asked to form the mere prosocial goal of "I want to cooperate with my counterpart!," and a second group to furnish this goal with a respective implementation intention: "And if I receive a proposal on how to share the island, then I will make a cooperative counterproposal!" Both groups were then subjected to a frame manipulation, whereby both members of the pair received a lossframe manipulation (i.e., each region's value was expressed in 
points that are lost when the region is given away). In addition, two control conditions were established: A first control condition contained pairs of negotiators who were not assigned prosocial goals and asked to negotiate under a loss frame; the second control condition also consisted of pairs of negotiators who were not assigned prosocial goals, but these pairs of negotiators were asked to negotiate under a gain frame (i.e., each region's value was expressed in points that are won when the region is kept). These two control conditions were used to establish the negative influence of loss vs. gain frames on joint profits. In addition, the loss-frame control condition served as a comparison group for the two critical experimental groups (i.e., the prosocial goal group and the prosocial goal plus implementation intention group).

When looking at the agreements achieved (i.e., level of joint outcomes), it was observed that pairs of loss-frame negotiators with a prosocial goal intention managed to somewhat reduce the resistance to concession making arising from the loss-frame negotiation context, but that only negotiators who furnished their prosocial goal intentions with respective implementation intentions were successful in completely abolishing the negative impact of the loss-frame negotiation context (i.e., showed a negotiation performance that was not different from that of gain-frame negotiators). In addition, action control via implementation intentions was found to be very efficient (i.e., implementation intentions abolished the negative effects of loss framing by leaving the negotiators' cognitive capacity intact); negotiators who had formed implementation intentions were more likely to use the cognitively demanding integrative negotiation strategy of logrolling (i.e., making greater concessions on low rather than high priority issues).

\section{Overcoming habitual behavioral responses}

The self-regulation of one's goal striving becomes difficult when habitual responses conflict with initiating and executing the needed goal-directed responses instrumental to goal attainment (e.g., Wood \& Neal, 2007, 2009; Ji \& Wood, 2007). In such cases, having willpower means asserting one's will to attain the chosen goal against unwanted habitual responses. But can the self-regulation strategy of forming ifthen plans help people to let their goals win out over their habitual responses? By assuming that action control by implementation intentions is immediate and efficient, and adopting a simple race horse model of action control (Gurney, Prescott, \& Redgrave, 2001a,b), people might be in a position to break habitualized responses by forming implementation intentions (e.g., if-then plans that spell out a response that is contrary to the habitualized response to the critical situation; Holland, Aarts, and Langendam, 2006).

Cohen, Bayer, Gollwitzer, and Jaudas (2008; Study 2; see also Miles \& Proctor, 2008) explored the suppression of habitual responses by implementation intentions in a laboratory experiment using the Simon task. In this paradigm, participants are asked to respond to a non-spatial aspect of a stimulus (i.e., whether a presented tone is high or low) by pressing a left or right key, and to ignore the location of the stimulus (i.e., whether it is presented on one's left or right side). The difficulty of this task is in ignoring the spatial location (left or right) of the tone in one's classification response (i.e., pressing a left or right response key; Simon, 1990). The cost in reaction times is seen when the location of the tone (e.g., right) and required key press (e.g., left) are incongruent, as people habitually respond to stimuli presented at the right or left side with the corresponding hand. Cohen et al. (2008; Study 2) found that implementation intentions eliminated the Simon effect for the stimulus that was specified in the ifcomponent of the implementation intention. Reaction times for this stimulus did not differ between the congruent and incongruent trials (i.e., they were fast throughout).

Still, one wonders whether action control by implementation intentions will always block habitual responses. Using a race horse metaphor, the answer has to be no. Whether the habitual response or the if-then guided response will win the race depends on the relative strength of the two behavioral orientations. If the habitual response is based on strong habits (Webb, Sheeran, \& Luszczynska, 2009; Wood \& Neal, 2007, 2009) and the if-then guided response is based on weak implementation intentions, then the habitual response should win over the if-then planned response, and the reverse should be true when weak habits are sent into a race with strong implementation intentions.

This implies that controlling behavior that is based on strong habits requires the formation of strong implementation intentions. Such enhancement of if-then plans can be achieved by various measures. One pertains to creating particularly strong links between situational cues (if-component) and goal-directed responses (then-component). A promising strategy has been suggested by Knäuper, Roseman, Johnson, and Krantz (2009; see also Papies, Aarts, \& de Vries, in press). They asked participants to use mental imagery when linking situational cues to goaldirected responses in their if-then plans, and found that the rate of initiation of the planned response increased by almost $50 \%$.

An alternative strategy to enhance implementation intention effects is linking plan formation with mental contrasting of a desired future and features of the present reality that stand in the way of realizing that future (Oettingen, Pak, \& Schnetter, 2001). Mental contrasting has been found to facilitate the detection of obstacles that could interfere with the realization of one's goals and it creates a readiness to form if-then plans to overcome such obstacles. Recent intervention studies taught participants to first use mental contrasting to identify obstacles to goal striving and then form if-then plans that used this obstacles in the if-part and an instrumental behavior to overcome them in the then-part. Findings indicated that rate of goal attainment was enhanced even for such habitualized behaviors as physical activity (Stadler, Oettingen, \& Gollwitzer, 2009) and snack food consumption (Adriaanse, Oettingen, Gollwitzer, Hennes, de Ridder, \& de Wit, 2009). In the latter study, the strength of the habitual response was measured via the self-report habit index (Verplanken \& Orbell, 2003); the effect of the intervention was obtained for both weak and strong snacking habits. In addition, combining mental contrasting with implementation intentions produced a greater reduction in snacking compared to a mere mental contrasting intervention and a mere implementation intentions intervention. 
Finally, one wonders whether there are certain formats of implementation intentions that are better suited to fight habits than others. For instance, an implementation intention that specifies the critical cue (i.e., one or many features of the context that commonly elicit the habitual behavior) in its if-part and an ignore-response in the then-part should have a good change to break even strong habits as the specified response (i.e., ignoring the critical cue) already fights the detection of the critical cue - the trigger of the habitual response (Schweiger Gallo et al., 2009). An implementation intention that specifies the critical cue and links it to an antagonistic response, on the other hand, sends this response into competition with the habitual response; here, it seems possible that a very strong habitual response could potentially outrun the antagonistic response specified in the implementation intention, in particular when the implementation intention is not backed up by additional measures such as mental contrasting. The worst format of an implementation intention for fighting habits seems to be the following: the if-part specifies the critical cue, whereas the then-part specifies the negation of the habitual behavior. Here, it seems possible that monitoring processes associated with the suppression of the habitual response may even lead to ironic effects (Wegner, 1994) in the sense that the habitual response gets strengthened.

So far, there is no systematic research on the effects of the format of implementation intentions on their potential to fight habits of different strengths. Such research is definitely needed. On the other hand, one should not forget that behavior change is possible also without changing bad habits; one can focus as well on the building of new habits in new situational contexts. With respect to this latter approach implementation intentions can guide goal striving without having to outrun habitual responses. The "delegation of control to situational cues principle" on which implementation intention effects are based can unfold its facilitative effects on goal striving in an undisturbed manner.

\section{Moderators of implementation intention effects}

Whenever consumers set out to use implementation intentions to improve decision making and the enactment of their decisions, it is important to be aware of the moderators of implementation intention effects discovered so far. These pertain to commitment to the respective goal intention and the if-then plan at hand, self-efficacy, and the personality factors of socially-prescribed perfectionism and conscientiousness.

\section{Commitment}

For implementation intention effects to occur people need to be strongly committed to the superordinate goal intention (e.g., Gollwitzer 1999; De Nooijer, De Vet, Brug, \& De Vries, 2006; Orbell, Hodgkins, \& Sheeran, 1997; Sheeran, Webb, \& Gollwitzer, 2005; Study 1; Verplanken \& Faes, 1999); also, the goal should be self-concordant (Koestner, Lekes, Powers, \& Chicoine, 2002) and the goal needs to be in a state of activation (Sheeran et al., 2005; Study 2; Cohen, Bayer, Jaudas, \& Gollwitzer, 2008). These prerequisites help to prevent mech- anistic plan enactment when people have already disengaged from the respective goal or find themselves pursuing different goals; in other words, the automaticity achieved by implementation intentions is a goal-dependent automaticity (Bargh, 1989). For example, in a Puzzle Task Study on the goaldependence of implementation intentions (Sheeran et al., 2005; Study 2), implementation intentions that specified how to be fast in solving the puzzles did not lead to faster responses when the goal to be accurate rather than fast was activated. However, when the goal to be fast rather than accurate was activated, these implementation intentions in fact did produce faster responses.

Moreover, the commitment to forming implementation intention needs to be strong (e.g., Achtziger, Bayer, \& Gollwitzer, 2009; Study 2) as well. When one doubts the appropriateness of forming implementation intentions, no implementation intention effects can be expected. In line with this assumption, Achtziger et al. (2009; Study 2) observed weaker implementation intention effects in participants who had been told that they had the type of personality that facilitates goal attainment by staying flexible (low plan commitment), as compared to participants who had been told that they had the type of personality that facilitates goal attainment by sticking to one's plans (high plan commitment). There may also be ways the individual can use to increase the commitment to an if-then plan she has already made (e.g., making one's if-then plans public; Deutsch \& Gerard, 1955); future research needs to explore such ways and their moderators. In any case, the requirement of commitment to the if-then plan supports the effectiveness of implementation intentions, by ensuring that incidental if-then plans do not impair flexibility that might be needed for goal attainment (e.g., Gollwitzer, Parks-Stamm, Jaudas, \& Sheeran, 2008).

\section{Self-efficacy}

A high level of perceived self-efficacy (Bandura, 1977, 1997 ) is also found to moderate implementation intention effects. Perceived self-efficacy is defined as "the belief in one's capabilities to organize and execute the courses of action required to produce given attainments" (Bandura, 1997, p. 3). Koestner et al. (2006) asked if the effects of implementation intentions on the attainment of self-generated personal goals can be bolstered for the long haul by simultaneously boosting selfefficacy. In this study, participants were randomly assigned to one of three treatment conditions. In the control condition, they completed an irrelevant goal task. In the implementation intention condition, participants made plans of when, where, and how to pursue their most important New Year's resolution. In the implementation intention plus self-efficacy boost condition, participants were additionally required to reflect on their actual New Year's resolutions using three different tasks designed to boost their self-efficacy: they had to think of past mastery experiences (i.e., situations when they achieved a similar goal), vicarious experiences (i.e., situations when a similar individual attained a similar goal), and means of social support (i.e., an individual encouraging their goal). Measuring goal progress via questionnaires e-mailed 20 weeks later, participants reported a significantly higher level of goal 
progress in the implementation intention plus self-efficacy boosting condition compared to the control condition as well as to the mere implementation intention condition. In a recent study by Wieber, Odenthal, and Gollwitzer (in press), high or low self-efficacy was manipulated by asking participants to solve low or high difficulty goal-relevant tasks. It was observed that high self-efficacy participants showed stronger implementation intention effects than low self-efficacy participants when goal striving was difficult but not when goal striving easy.

\section{Personality factors}

\section{Socially-prescribed perfectionism}

Finally, personality factors have been examined as moderators of implementation intention effects in two lines of research (Powers, Koestner, \& Topciu, 2005; Webb, Christian, \& Armitage, 2007). In the first set of studies on the interaction between personality traits and if-then planning factors, perfectionism was examined. Socially-prescribed perfectionism moderated the effectiveness of implementation intentions (Powers et al., 2005), resulting in poorer goal achievement among sociallyprescribed perfectionists. Similar to self-oriented perfectionism, socially-prescribed perfectionism entails setting high personal standards and evaluating oneself stringently. But whereas the standards for self-oriented perfectionists are set by the people themselves, socially-prescribed perfectionists try to conform to standards and expectations that are prescribed by others. A high level of socially-prescribed perfectionism is related to depression, anxiety disorders, and obsessive-compulsive symptoms (e.g., Powers, Zuroff, \& Topciu, 2004). In the first study, participants who scored high on the socially-prescribed perfectionism subscale of the Multidimensional Perfectionist Scale (MPS; Hewitt, Flett, Turnbull-Donovan, \& Mikail, 1991) reported poorer progress after 2 and 4 weeks on their New Year's resolutions (i.e., three personal goals) when they formed implementation intentions than when they received control instructions. In a second study, participants with high scores on socially-prescribed perfectionism who formed implementation intentions not only reported less goal progress, but were also less satisfied with their personal goal progress and thought that others were less satisfied with their progress, than participants who formed implementation intentions but scored low on this subscale. However, for participants with self-oriented perfectionism, forming implementation intentions actually improved goal progress (Powers et al., 2005; Study 2).

\section{Conscientiousness}

In a second line of research on personality factors, conscientiousness was examined (Webb, Christian, \& Armitage, 2007). In an experimental study using undergraduate students, attendance in class was studied as a function of conscientiousness, openness to experience, goal intentions, and implementation intentions. Most importantly, the implementation intention effects were moderated by participants' personality trait of conscientiousness. While class attendance of highly conscientious students was not changed by forming implementation intentions (it was high to begin with and stayed high), low and moderately conscientious people significantly benefited from planning when, where, and how they would attend class (their class attendance rates were low to begin with and increased to high when implementation intentions were formed).

\section{Conclusion}

We conclude that making consumer decisions and implementing these decisions can greatly benefit from applying selfregulatory strategies. The strategy that we have discussed in the present paper is forming if-then plans or implementation intentions. Such plans specify critical cues for responses that could improve the quality of consumers' decisions and enhance the likelihood of translating those decisions into action. Decision quality can be improved by enhancing attention control, promoting the elaboration of the attended-to information, and by overcoming unwanted influences on the decision making process. Decision realization can be improved by helping people get started with action initiation, by shielding goal progress from disruptions, by early disengagement from ineffective striving, and by conserving one's capacity for further self-regulation. Moreover, when situations demand increased willpower (e.g., cognitively challenging tasks, competitive contexts, and antagonistic habits), implementation intentions appear to be effective in boosting goal attainment. The psychological principle behind the strategy of forming implementation intentions is that of delegating control to situational cues thus reducing the burden on the person's conscious, effortful control. As a result, people are better equipped to decide what they want, and do what they want to do. We grant that the research conducted so far on implementation intention effects and their underlying processes have mostly targeted issues (e.g., spider fear, academic test performance, and drug adherence) that do not readily qualify as consumer-relevant. Still, it seems justified to generalize these findings to consumer-related issues as the basic principle underlying implementation intention effects (i.e., facilitating goal striving by delegating its control to critical situational cues) is content free, and thus should unfold positive effects in the realm of consumer decision making and behavior as well.

\section{References}

Aarts, H., Dijksterhuis, A., \& Midden, C. (1999). To plan or not to plan? Goal achievement or interrupting the performance of mundane behaviors. European Journal of Social Psychology, 29, 971-979.

Achtziger, A., Bayer, U. C., \& Gollwitzer, P. M. (2009). Committing to implementation intentions: Attention and memory effects for selected situational cues. Manuscript submitted for publication.

Achtziger, A., Gollwitzer, P. M., \& Sheeran, P. (2008). Implementation intentions and shielding goal striving from unwanted thoughts and feelings. Personality and Social Psychology Bulletin, 34, 381-393.

Adriaanse, M. A., Oettingen, G., Gollwitzer, P. M., Hennes, E. P., de Ridder, D. T. D., \& de Wit, J. B. F. (2009). When planning is not enough: Breaking unhealthy snacking habits with mental contrasting and implementation intentions (MCII). European Journal of Social Psychology.

Armitage, C. J. (2004). Evidence that implementation intentions reduce dietary fat intake: A randomized trial. Health Psychology, 23, 319 - 323.

Baker, R. C., \& Kirschenbaum, D. S. (1998). Weight control during the holidays: Highly consistent self-monitoring as a potentially useful coping mechanism. Health Psychology, 17, 367-370. 
Bandura, A. (1977). Self-efficacy: Toward a unifying theory of behavioral change. Psychological Review, 84, 191-215.

Bandura, A. (1997). Self-efficacy: The exercise of control. New York: W. H. Freeman \& Co.

Bargh, J. A. (1989). Conditional automaticity: Varieties of automatic influence in social perception and cognition. In J. S. Uleman, \& J. A. Bargh (Eds.), Unintended thought (pp. 3-51). New York: Guilford Press.

Bargh, J. A., \& Chartrand, T. L. (2000). The mind in the middle: A practical guide to priming and automaticity research. In H. T. Reis, \& C. M. Judd (Eds.), Handbook of research methods in social and personality psychology New York: Cambridge University Press.

Bayer, U. C., Achtziger, A., Gollwitzer, P. M., \& Moskowitz, G. (2009). Responding to subliminal cues: Do if-then plans cause action preparation and initiation without conscious intent? Social Cognition, 27, 183-201.

Bayer, U. C., \& Gollwitzer, P. M. (2007). Boosting scholastic test scores by willpower: The role of implementation intentions. Self and Identity, 6, 1-19.

Bayer, U. C., Gollwitzer, P. M., \& Achtziger, A. (2009). Staying on track: Planned goal striving is protected from disruptive internal states. Manuscript under review.

Bless, H. (2001). Mood and the use of general knowledge structures. In L. L. Martin, \& G. L. Clore (Eds.), Theories of mood and cognition: A user's guidebook (pp. 9-26). Mahwah, NL: Erlbaum.

Bless, H., \& Fiedler, K. (1995). Affective states and the influence of activated general knowledge. Personality and Social Psychology Bulletin, 21, 766-778.

Beck, A. T. (1995). Cognitive therapy: Past, present, and future. In M. J. Mahoney (Ed.), Constructive psychotherapies: Theory, research, and practice (pp. 29-40). New York: Springer Publishing Company.

Bobocel, D. R., \& Meyer, J. P. (1994). Escalating commitment to a failing course of action: Separating the roles of choice and justification. Journal of Applied Psychology, 79, 360-363.

Bottom, W. P., \& Studt, A. (1993). Framing effects and the distributive aspect of integrative bargaining. Organizational Behavior and Human Decision Processes, 56, 459-474.

Brandstätter, V., Lengfelder, A., \& Gollwitzer, P. M. (2001). Implementation intentions and efficient action initiation. Journal of Personality and Social Psychology, 81, 946 960.

Brickenkamp, R., \& Zillmer, E. (1998). The d2 test of attention. Zürich: H \& H Publisher.

Brown, I., Sheeran, P., \& Reuber, M. (2009). Enhancing anti-epileptic drug adherence: A randomized controlled trial. Epilepsy and Behavior.

Chaiken, S. (1979). Communicator physical attractiveness and persuasion. Journal of Personality and Social Psychology, 37, 1387-1397.

Chen, S., \& Chaiken, S. (1999). The heuristic-systematic model in its broader context. In S. Chaiken, \& Y. Trope (Eds.), Dual-process theories in social psychology (pp. 73-96). New York: Guilford.

Cohen, A-L., Bayer, U. C., Jaudas, A., \& Gollwitzer, P. M. (2008). Self-regulatory strategy and executive control: Implementation intentions modulate task switching and Simon task performance. Psychological Research, 72, 12-26.

Cohen, J. (1992). A power primer. Psychological Bulletin, 112, 155-159.

Cooper, J., \& Neuhaus, I. M. (2000). The "hired gun" effect: Assessing the effect of pay, frequency of testifying, and credentials on the perception of expert testimony. Law and Human Behavior, 24, 149-171.

de Nooijer, J., de Vet, E., Brug, J., \& de Vries, N. K. (2006). Do implementation intentions help to turn good intentions into higher fruit intakes? Journal of Nutrition Education and Behavior, 38, 25-29.

Deutsch, M., \& Gerard, H. B. (1955). A study of normative and informational social influences upon individual judgment. Journal of Abnormal and Social Psychology, 51, 629-636.

Fazio, R. H., \& Zanna, M. P. (1981). Direct experience and attitude-behavior consistency. Advances in Experimental Social Psychology, 14, 161-189.

Fox, E., Russo, R., Bowles, R., \& Dutton, K. (2001). Do threatening stimuli draw or hold visual attention in subclinical anxiety? Journal of Experimental Psychology: General, 130, 681-700.

Gawrilow, C., \& Gollwitzer, P. M. (2008). Implementation intentions facilitate response inhibition in ADHD children. Cognitive Therapy and Research, $32,261-280$.

Gilbert, S., Gollwitzer, P. M., Cohen, A-L., Oettingen, G., \& Burgess, P. W. (2009). Separable brain systems supporting cued versus self-initiated realization of delayed intentions. Journal of Experimental Psychology: Learning, Memory, and Cognition, 35, 905--915.

Gollwitzer, P. M. (1993). Goal achievement: The role of intentions. European Review of Social Psychology, 4, 141-185.

Gollwitzer, P. M. (1999). Implementation intentions: Strong effects of simple plans. American Psychologist, 54, 493--503

Gollwitzer, P. M., Bayer, U. C., \& McCulloch, C. (2005). The control of the unwanted. In R. Hassin, J. Uleman, \& J. A. Bargh (Eds.), The new unconscious (pp. 485-515). Oxford: Oxford University Press.

Gollwitzer, P. M., \& Brandstätter, V. (1997). Implementation intentions and effective goal pursuit. Journal of Personality and Social Psychology, 73, 186-199.

Gollwitzer, P. M., Parks-Stamm, E. J., Jaudas, A., \& Sheeran, P. (2008). Flexible tenacity in goal pursuit. In J. Shah, \& W. Gardner (Eds.), Handbook of motivation science (pp. 325-341). New York: Guilford Press.

Gollwitzer, P. M., \& Schaal, B. (1998). Metacognition in action: The importance of implementation intentions. Personality and Social Psychology Review, 2, 124-136.

Gollwitzer, P. M., \& Sheeran, P. (2006). Implementation intentions and goal achievement: A meta-analysis of effects and processes. Advances in Experimental Social Psychology, 38, 69-119.

Greenwald, A. G., McGhee, D. E., \& Schwartz, J. L. K. (1998). Measuring individual differences in implicit cognition: The Implicit Association Test. Journal of Personality and Social Psychology, 74, 1464-1480.

Gurney, K., Prescott, T. J., \& Redgrave, P. (2001a) A computational model of action selection in the basal ganglia I: A new functional anatomy. Biological Cybernetics, 84, 401-410.

Gurney, K., Prescott, T. J., \& Redgrave, P. (2001b) A computational model of action selection in the basal ganglia II: Analysis and simulation of behaviour. Biological Cybernetics, 84, 411-423.

Henderson, M., Gollwitzer, P. M., \& Oettingen, G. (2007). Implementation intentions and disengagement from a failing course of action. Journal of Behavioral Decision Making, 20, 81-102.

Hewitt, P. L., Flett, G. L., Turnbull-Donovan, W., \& Mikail, S. F. (1991). The multidimensional perfectionism scale: Reliability, validity, and psychometric properties in psychiatric samples. Psychological Assessment, 3, 464-468.

Higgins, E. T., \& Rhodes, W. S. (1979). "Saying is believing": Effects of modification on memory and liking for the person described. Journal of Personality and Social Psychology, 14, 363-378.

Holland, R. W., Aarts, H., \& Langendam, D. (2006). Breaking and creating habits on the working floor: A field experiment on the power of implementation intentions. Journal of Experimental Social Psychology, 42, 776-783.

Janis, I. L. (1968). Attitude change via role playing. In R. Abelson, E. Aronson, W. McGuire, T. Newcomb, M. Rosenberg, \& P. Tennenbaum (Eds.), Theories of cognitive consistency: A sourcebook (pp. 810-818). Rand-McNally: Chicago.

Ji, M. F., \& Wood, W. (2007). Purchase and consumption habits: Not necessarily what you intend. Journal of Consumer Psychology, 17, 261-276.

Kardes, F. R., Cronley, M. L., \& Posavac, S. S. (2005). Using implementation intentions to increase new product consumption: A field experiment. In F. R. Kardes, P. M. Paul, \& J. Nantel (Eds.), Applying social cognition to consumer-focused strategy (pp. 219-233). Mahwah, NJ: Lawrence Erlbaum.

Kavanagh, D. J., Andrade, J., \& May, J. (2005). Imaginary relish and exquisite torture: The elaborated intrusion theory of desire. Psychological Review, $112,446-467$.

Koestner, R., Horberg, E. J., Gaudreau, P., Powers, T., Di Dio, P., Bryan, C., et al. (2006). Bolstering implementation plans for the long haul: The benefits of simultaneously boosting self-concordance or self-efficacy. Personality and Social Psychology Bulletin, 32, 1547-1558.

Koestner, R., Lekes, N., Powers, T. A., \& Chicoine, E. (2002). Attaining personal goals: Self-concordance plus implementation intentions equals success. Journal of Personality and Social Psychology, 83, 231-244.

Kramer, T., \& Yoon, S. O. (2007). Approach-avoidance motivation and the use of affect as information. Journal of Consumer Psychology, 17, 128-138.

Knäuper, B., Roseman, M., Johnson, P., \& Krantz, L. (2009). Using mental imagery to enhance the effectivenes of implementation intentions. Current Psychology, 28, 181-186. 
Lengfelder, A., \& Gollwitzer, P. M. (2001). Reflective and reflexive action control in frontal lobe patients. Neuropsychology, 15, 80-100.

Martin, J., Sheeran, P., Slade, P., Wright, A., \& Dibble, T. (in press). Implementation intention formation reduces consultations for emergency contraception and pregnancy testing among teenage women. Health Psychology.

Martijn, C., Alberts, H., Sheeran, P., Peters, G. J. Y., Mikolajczak, Y., \& de Vries, N. K. (2008). Blocked goals, persistent action: Implementation intentions promote tenacious goal striving. Journal of Experimental Social Psychology, 44, 1137-1143

Mendoza, S. A., Gollwitzer, P. M., \& Amodio, D. M. (2009). Reducing the expression of implicit stereotypes: Reflexive control through implementation intentions. Personality and Social Psychology Bulletin.

Metcalfe, J., \& Mischel, W. (1999). A hot/cool-system analysis of delay of gratification: Dynamics of willpower. Psychological Review, 106, 3-19.

Miles, J. D., \& Proctor, R. W. (2008). Improving performance through implementation intentions: Are preexisting response biases replaced? Psy chonomic Bulletin \& Review, 15, 1105-1110.

Miltenberger, R. G., Fuqua, W. R., \& Woods, D. W. (1998). Applying behavio analysis to clinical problems: Review and analysis of habit reversal. Journal of Applied Behavior Analysis, 31, 447-469.

Mischel, W., \& Patterson, C. J. (1978). Effective plans for self-control in children. In W. A. Collins (Ed.), Minnesota symposium on child psychology, Vol. 11 (pp. 199-230). Hillsdale, NJ: Lawrence Erlbaum Associates, Inc.

Muraven, M., \& Baumeister, R. F. (2000). Self-regulation and depletion of limited resources. Does self-control resemble a muscle? Psychological Bulletin, 126, 247-259.

Musa, C., Lepine, J. P., Clark, D. M., Mansell, W., \& Ehlers, A. (2003) Selective attention in social phobia and the moderating effect of a concurrent depressive disorder. Behaviour Research and Therapy, 41, 1043-1054.

Navon, D., \& Margalit, B. (1983). Allocation of attention according to informativeness in visual recognition. Quarterly Journal of Experimental Psychology, 35A, 497-512.

Nosek, B. A., \& Banaji, M. R. (2001). The Go/No-Go Association Task. Social Cognition, 19, 625-666.

Oettingen, G., Hoenig, G, \& Gollwitzer, P. M. (2000). Effective self-regulation of goal attainment. International Journal of Educational Research, 33 , $705-732$.

Oettingen, G., Pak, H., \& Schnetter, K. (2001). Self-regulation of goal-setting: Turning free fantasies about the future into binding goals. Journal of Personality and Social Psychology, 80, 736-753

Olekalns, M. (1997). Situational cues as moderators of the frame-outcome relationship. British Journal of Social Psychology, 36, 191-209.

Orbell, S., Hodgkins, S., \& Sheeran, P. (1997). Implementation intentions and the theory of planned behavior. Personality and Social Psychology Bulletin, $23,945-954$.

Palayiwa, A., Sheeran, P., \& Thompson, A. R. (in press). "Word will never hurt me": Implementation intentions regulate attention to stigmatizing comments about appearance. Journal of Social and Clinical Psychology.

Papies, E., Aarts, H., \& de Vries, N. K. (in press). Grounding your plans: Implementation intentions go beyond the mere creation of goal-directed associations. Journal of Experimental Social Psychology.

Parks-Stamm, E., Gollwitzer, P. M., \& Oettingen, G. (2007). Action control by implementation intentions: Effective cue detection and efficient response initiation. Social Cognition, 25, 248-266.

Paul, I., Gawrilow, C., Zech, F., Gollwitzer, P. M., Rockstroh, B., Odenthal, G., Kratzer, W., \& Wienbruch, C. (2007). If-then planning modulates the P300 in children with attention deficit hyperactivity disorder. NeuroReport, 18, 653-657

Petty, R. E., Caccioppo, J. T., \& Goldman, R. (1981). Personal involvement as a determinant of argument-based persuasion. Journal of Personality and Social Psychology, 4I, 847-855

Petty, R. E., \& Wegener, D. T. (1999). The elaboration likelihood model: Current status and controversies. In S. Chaiken, \& Y. Trope (Eds.), Dualprocess theories in social psychology (pp. 41-72). New York: Guilford.

Powers, T. A., Koestner, R., \& Topciu, R. A. (2005). Implementation intentions, perfectionism, and goal progress: Perhaps the road to hell is paved with good intentions. Personality and Social Psychology Bulletin, 31, 902-912.
Powers, T. A., Zuroff, D. C., \& Topciu, R. A. (2004). Covert and overt expressions of self-criticism and perfectionism and their relation to depression. European Journal of Personality, 18, 61-72.

Prochaska, J. O., DiClimente, C. C., \& Norcross, J. C. (1992). In search of how people change: Applications to addictive behavior. American Psychologist, $47,1102-1114$

Raven, J. C. (1976). Advanced progressive matrices. Set II. Oxford: Oxford Psychologists Press.

Rogers, R. D., Everitt, B. J., Baldacchino, A., Blackshaw, A. J., Swainson, R., Wynne, K., Baker, N. B., Hunter, J., Carthy, T., Booker, E., London, M., Deakin, J. F. W., Sahakian, B. J., \& Robbins, T. W. (1999). Dissociable deficits in the decision-making cognition of chronic amphetamine abusers, opiate abusers, patients with focal damage to prefrontal cortex, and trytophan-depleted normal volunteers: Evidence for monoaminergic mechanisms. Neuropsychopharmacology, 20, 322-339.

Schweiger Gallo, I., Keil, A., McCulloch, K. C., Rockstroh, B., \& Gollwitzer, P. M. (2009). Strategic automation of emotion regulation. Journal of Personality and Social Psychology, 96, 11-31.

Semin, G. R., \& Fiedler, K. (1991). The linguistic category model, its bases, applications and range. European Review of Social Psychology, 2, 1-30.

Sheeran, P., Aubrey, R., \& Kellett, S. (2007). Increasing attendance for psychotherapy: Implementation intentions and the self-regulation of attendance-related negative affect. Journal of Consulting and Clinical Psychology, 75, 853-863.

Sheeran, P., \& Orbell, S. (1999). Implementation intentions and repeated behaviours: Augmenting the predictive validity of the theory of planned behaviour. European Journal of Social Psychology, 29, 349-369.

Sheeran, P., Webb, T. L., \& Gollwitzer, P. M. (2005). The interplay between goal intentions and implementation intentions. Personality and Social Psychology Bulletin, 31, 87-98.

Simon, J. R. (1990). The effects of an irrelevant directional cue on human information processing. In R. W. Proctor, \& T. G. Reeve (Eds.), Stimulusresponse compatibility: An integrative perspective (pp. 31-86). Amsterdam: North-Holland.

Stadler, G., Oettingen, G., \& Gollwitzer, P. M. (2009). Physical activity in women. Effects of a self-regulation intervention. American Journal of Preventive Medicine, 36, 29-34.

Stewart, B. D., \& Payne, K. B. (2008). Bringing automatic stereotyping under control: Implementation intentions as efficient means of thought control. Personality and Social Psychology Bulletin, 34, 1332-1345.

Trötschel, R., \& Gollwitzer, P. M. (2007). Implementation intentions and the willful pursuit of goals in negotiations. Journal of Experimental Social Psychology, 43, 519-598.

Verplanken, B., \& Faes, S. (1999). Good intentions, bad habits, and effects of forming implementation intentions on healthy eating. European Journal of Social Psychology, 29, 591-604.

Verplanken, B., \& Orbell, S. (2003). Reflections on past behavior: A self-report index of habit strength. Journal of Applied Social Psychology, 33, 1313-1330.

Vohs, K. D., Schmeichel, B. J., Nelson, N. M., Nelson, N. M., Baumeister, R. F Twenge, J. M., \& Tice, D. M. (2008). Making choices impairs subsequent self-control: A limited-resource account of decision making, self-regulation, and active initiative. Journal of Experimental Social Psychology, 94, 883-898.

Webb, T. L., Christian, J., \& Armitage, C. J. (2007). Helping students turn up for class: Does personality moderate the effectiveness of an implementation intention intervention? Learning and Individual Differences, 17, $316-327$.

Webb, T. L., Onanaiye, M., Sheeran, P., Reidy, J., \& Lavda, S. (2009). Using implementation intentions to modify the effects of social anxiety on attention and responses to evaluative situations. Personality and Social Psychology Bulletin.

Webb, T. L., \& Sheeran, P. (2003). Can implementation intentions help to overcome ego-depletion? Journal of Experimental Social Psychology, 39, 279--286.

Webb, T. L., \& Sheeran, P. (2004). Identifying good opportunities to act: Implementation intentions and cue discrimination. European Journal of Social Psychology, 34, 407-419. 
Webb, T. L., \& Sheeran, P. (2006). Does changing behavioural intentions engender behavior change? A meta-analysis of the experimental evidence. Psychological Bulletin, 132, 249-268.

Webb, T. L., \& Sheeran, P. (2007). How do implementation intentions promote goal attainment? A test of component processes. Journal of Experimental Social Psychology, 43, 265-268.

Webb, T. L., \& Sheeran, P. (2008). Mechanisms of implementation intention effects: The role of intention, self-efficacy, and accessibility of plan components. British Journal of Social Psychology, 47, 373-395.

Webb, T. L., Sheeran, P., \& Luszczynska, A. (2009). Planning to break unwanted habits: Habit strength moderates implementation intention effects on behavior change. British Journal of Social Psychology, 48, 507-523.

Webb, T. L., Sheeran, P., \& Pepper, J. (2009). Overcoming the expression of implicit attitudes via implementation intentions. Manuscript under review.

Webb, T. L., Sheeran, P., Totterdell, P., Mansell, W., \& Baker, S. (2009). Overcoming the effect of mood on risky and impulsive behavior. Manuscript under review.
Wegner, D. M. (1994). Ironic processes of mental control. Psychological Review, 101, 34-52.

Wieber, F., Odenthal, G., \& Gollwitzer, P. M. (2009). Self-efficacy feelings moderate implementation intention effects. Self and Identity. doi: $10.1080 / 15298860902860333$.

Wieber, F., \& Sassenberg, K. (2006). I can't take my eyes off of it-attention attraction effects of implementation intentions. Social Cognition, 24, 723-752.

Wood, W., \& Neal, D. T. (2007). A new look at habits and the habit-goal interface. Psychological Review, 114, 842-862.

Wood, W., \& Neal, D. T. (2009). The habitual consumer. Journal of Consumer Psychology (this issue). doi:10.1016/j.jcps.2009.08.003.

Wyer, R. S., Hung, I. W., \& Jiang, Y. W. (2008). Visual and verbal processing strategies in comprehension and judgment. Journal of Consumer Psychology, $18,244-257$

Yoon, C., Cole, C. A., \& Lee, M. P. (2007). Consumer decision making and aging: Current knowledge and future directions. Journal of Consumer Psychology, 19, 2-16. 